THE PRIVATE PHYSIOTHERAPIST IN SPORTS MEDICINE

D. CHAPMAN, M.C.S.P.

Hon. Sec., The Association of Chartered Physiotherapists in Sports Medicine

Having just returned from Florida and the Bahamas on a three week rugby football tour I found on my desk an invitation, or perhaps rather an instruction, from Peter Sperryn to present to you this morning a short paper on the Private Physiotherapist in Sports Medicine.

I mention the tour deliberately to make the point that it is only being a physiotherapist in private practice that allows me the time and money to indulge in such exotic trips at least once a year.

We have heard from Dr. Ian Adams of the problems of treating the injured athlete through the over worked and creaking National Health Service Casualty Departments. I believe that of the nine experimental sports injuries clinics set up some time ago four survive, the other five, victims of manpower and financial shortages. It is because of this and the unsatisfactory service that the injured sportsmen frequently receives through the N.H.S. that the private practitioner finds that there is a part to play.

I think that almost without exception all my colleagues in private practice have, after qualification, served their time in the National Health Service, but because of frustrations, mainly financial, have felt obliged to break forth on their own. These people who have had the drive and initiative to take such a funda $\frac{\text { क्र }}{2}$ mental step have put themselves into a position of sup? plying services to a clientele who are paying their ownis fees. When patients pay, they expect results. No results $\vec{O}$ no fees. Most of my colleagues in private practice havesurvived and $I$ think it fair therefore to assume that the are at least competant.

There are $\mathbf{2 4 0}$ members on the list of the Association of Chartered Physiotherapists in Sports Medicine and approximately half of these are in private practice. We therefore, have some 120 private practitioners scatterec in all parts of the country who have the facilities and some experience and enthusiasm for the treatment of the injured competitor.

In almost every practice there is a special scale of fee for the young athlete, and the enthusiastic practitione makes little, if any money from the treatment of the amateur.

응 $\frac{\text { D }}{6}$

We recognize that the facilities we have are far from perfect and indeed are incomplete and I like to thit that we recognize our own limitations. Despite this, the private practitioners in sports medicine do at least offes the facilities they have and in proper collaboration witt doctors in the vicinity, both in general and in consulting practice, its something upon which to build.

Brit. J. Sports Med. - Vol. 11, No. 3, September 1977, p. 146

\title{
ICE IN THE TREATMENT OF SPORTS INJURIES
}

Yvonne WOOTTON-WHITLING, M.C.S.P.

Physiotherapy Dept., Hillingdon Hospital, Uxbridge, Middlesex

Cooling, when used as a mode of treatment, has a number of different physiological effects, and it is important to decide what effect is required in order to select the most suitable treatment modality.

It seems reasonable, therefore, to divide the injuries which might be met with in a sporting context into three groups which reflect the pathological state of the injured tissue.

The first group is made up of ACUTE injuries within the first few hours of their occurrence. These are charac- terised by cell damage and the rupture of blood vessets and the primary aim of treatment is to reduce to minimum the formation of haematoma and oedema. combination of compression, elevation, rest and pros longed cooling of the limb with melting ice or cold wateip is employed to achieve the maximum possible reductiog of blood flow in the deep structures, and the loc slowing of metabolic processes.

When the acute stage has passed, these same injuries may be classified as SUBACUTE and now the judicious use of ice towels or packs can help the return to norm 
function by reducing the pain and muscle spasm which so often hinders progress.

The third, or CHRONIC group of injuries includes all the typical sporting overuse injuries in which a "cold" fibrosis is established. Many of the procedures used in the Physiotherapy department to initiate an active in flammatory response in this fibrotic situation are painfu in the extreme, and the counter-irritant and anaesthetio. effects of ice can make the necessary treatments bette: tolerated by the patient.

\title{
BOOK REVIEW
}

\section{GENETIC AND ANTHROPOLOGICAL STUDIES OF OLYMPIC ATHLETES}

\author{
A. L. de GARAY, L. LEVINE and J. E. LINDSAY CARTER \\ 1974 (Published in U.K. November 1976) \\ Academic Press Inc., New York, San Francisco \& London. \\ $\$ 14.50 £ 8.85$
}

The Olympic Games in Mexico in 1968 was the last chance there was of carrying out investigations upon Olympic athletes at the venue of the Games before the mass murder in Munich forced stringent security so that camps became military establishments instead of relaxed communities where there was freedom of movement and the ability of accredited scientific teams to undertake work. The altitude problem also meant that many of the competitors? especially in endurance events, took the chance of arriving early to undergo some degree of acclimatisation, and were willing to cooperate in being submitted to non-stressing investigations.

Of the 6,084 athletes at Mexico, the research team invited 4,168 to attend the centre for study. 1,265 (20.8\% actually attended, and it is upon this sample that the study is based though some pilot work was done before the Games on Mexicans of various racial backgrounds, both for comparison as a control group, and for the standardisation. techniques and apparatus. The response from the different countries varied a great deal; $54 \%$ from Mexico, 36\% from Canada, 6.7\% from the U.K., 0 from France! Most were caucasians, 718 compared with 235 negroids, 87 mongoloid? and 221 mestizos. 148 were female. Athletes were drawn from all events except equestrian, in which horses played the main part. The studies made on these athletes were carried out by independent teams, working in close collaboratio with each other, and carrying out a complete testing schedule on each subject. This was a big improvement on the methods adopted in previous studies where each team selected its own subjects, and frequently failed to pass the subject on to another team carrying out another type of investigation. The testing at Mexico obviously cost a lot of money, and was performed with an efficiency that can only be envied by those of us who have tried to carry out investigations on other occasions on a shoe-string budget and with little official backing from the organisers.

The first investigating team concentrated on the assessment of physique. The somatotyping technique used was that? of Barbara Honeyman Heath and Lindsay Carter, both of whom carried out much of the work themselves, though the actual measurements were performed mainly by Johanna Faulhaber and her fellow Mexicans. Using a differen's somatotype technique makes direct comparison with Jim Tanner's "Physique of the Olympic Athlete" rather difficult, though there are no very big differences in rating between the techniques with young adults away from the extremes of physique. Well over half the book is devoted to the production of the results of this study, and most detailed tables are given, analysing these results. These tables will prove most useful to any future research worker wanting detaile comparisons, but to the casual reader they may appear no more exciting than reading logarithm tables.

Another team investigated the place in the family of the Olympic athlete. This did not lead to any firm conclusionsi the parents' athletic ability did not seem to be of significance, and second children seemed to succeed better than eldest, but as this study was based upon athletes' statements, and they tended to belittle any excellence in sport of parents or siblings, accurate results could not be expected. The ability to taste such substances as phenylthiourea is añ inherited characteristic, and might be linked to thyroid function. Again, the results were rather inconclusive, but the tests took little time to perform, were not unpleasant, and laid foundations for future research.

Genetic studies were also carried out on the distribution of blood groups, which showed a higher proportion of Group B than would be expected in an English population (15\%). Of special interest were the haemoglobin studies which included the surprising observation that 11 of the negroid athletes displayed Haemoglobin A.S. phenotypeet 